\title{
ARTIGOS
}

\section{REAPROPRIAÇÃO DO DIREITO DE EXISTIR: ATRAVESSAMENTOS SOCIAIS NA VIDA DE PESSOAS TRANS}

\author{
Henrique de Souza Bitelo ${ }^{1}$ \\ Marina Ortolan Araldi ${ }^{2}$
}

Resumo: Por escaparem às bases da lógica cisheteronormativa, as pessoas trans se encontram mais propensas à vulnerabilidade social, o que pode resultar no enfrentamento de diversas formas de violência. Para compreender os atravessamentos sociais em suas vidas, foram entrevistados três jovens que residem na região metropolitana de Porto Alegre - RS e que se encontram em diferentes posições dentro do espectro das identidades trans. Os dados foram coletados a partir de entrevistas semiestruturadas e analisados através de uma Análise Crítica do Discurso. A partir de um processo de singularização, constatou-se que há um movimento ativo de resistência que persegue a reapropriação coletiva da potência da vida. Com isso, pretende-se gerar novos modos de vida, conquistar seus direitos de existir e a transformar suas realidades.

Palavras-chave: Pessoas Trans, Gênero, Transfobia, Social, Psicologia.

\section{REAPPROPRIATION OF THE RIGHT TO EXIST: SOCIAL CROSSINGS IN THE LIFE OF TRANS PERSONS}

Abstract: By escaping the impositions of the cisheteronormative logic, Trans Persons find themselves in social vulnerability and exposed to different types of violence. Thus, three young people who live in the metropolitan region of Porto Alegre - RS and who are in different positions within the spectrum of the trans identities were interviewed to understand how the social cross their lifes. The data were collected from semi-structured interviews and analyzed using a Critical Discourse Analysis. From a process of singularization, it has been acknowledged that there is an active movement of resistance pursuing the collective reappropriation of the power of life. Therefore, this process intends to generate new ways of living and to conquer their rights to exist, transforming their realities.

Key-words: Trans Person, Gender, Transfobia, Social, Psychology.

\section{INTRODUÇÃO}

Há indícios de reconhecimento e aceitação da diversidade de identidades e performances de gênero em diferentes culturas antigas. Porém, por efeito de opressões, ocidentalizações e colonialismos, é consolidada uma desigualdade sistêmica que levou à

\footnotetext{
${ }^{1}$ Psicólogo graduado pela Universidade La Salle - RS.

2 Mestre em Psicologia Clínica pela Universidade do Vale do Rio dos Sinos, docente do curso de psicologia da Universidade La Salle - RS.
}

Vol. 02, N. 04, Out. - Dez., $2019 \cdot$ www.revistas.unilab.edu.br/index.php/rebeh 
exclusão dos que são diferentes do padrão idealizado - homem-branco-cis-hetero (APA, 2015). As múltiplas identidades que escapam ao modelo pré-concebido foram reprimidas em seus direitos básicos, tiveram seus desejos invisibilizados e silenciados, afastando-as RE El geograficamente e simbolicamente a partir de diferentes estratégias de exclusão social

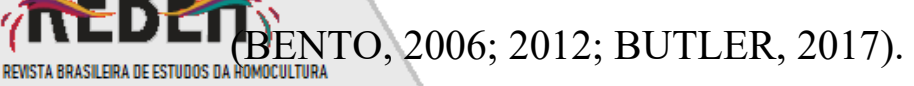

Com base nesses aspectos se pode refletir sobre as identidades trans, ou seja, identidades em que o gênero difere do sexo biológico. Partindo do pressuposto de que gênero é o efeito de um ato, de uma performance, que repetida em um espaço externo encena significações estabelecidas socialmente, é possível identificar que não há uma identidade preexistente. As identidades de gênero se produzem e se reproduzem a todo instante a partir de atos repetitivos de estilização dos corpos, criando a ilusão de um eu estável. Por não se submeterem às formas de controle da vida cotidiana, pessoas trans buscam se reapropriar do direito de existir (BUTLER, 2017; ARÁN, 2006; BENTO, 2012).

Desde os anos 2000, são diversos os avanços na jurisprudência brasileira a respeito dessa temática, destacando-se a autorização para pessoas trans alterarem seu nome e gênero no registro civil. Em 2013 foi publicada a Portaria $N^{\circ} 2.803$, que redefine e amplia o Processo Transexualizador no Sistema Único de Saúde (SUS). Essa portaria determinou ao Ministério da Saúde o cumprimento integral de medidas necessárias para possibilitar a realização no SUS de todos os procedimentos médicos para garantir a cirurgia de redesignação genital (BRASIL, 2013). Em 2018, o Provimento N. 73, regulamentou a alteração em certidão sem a obrigatoriedade da comprovação da cirurgia de redesignação genital nem de decisão judicial (CNJ, 2018). Até esta data, era necessário um atestado médico que comprovasse "uma verdade real baseada na transexualidade enquanto diagnóstico psiquiátrico" (CIDADE; BICALHO, 2017, p.170).

Apesar destes avanços, uma pesquisa realizada em 2017 pela Associação Nacional de Travestis e Transexuais (ANTRA) apontou que o Brasil continua sendo o país com maior número de assassinatos de pessoas LGBTs no mundo, sendo a população trans a mais afetada. Corroborando esta informação, no ano da pesquisa, 179 LGBTs foram mortos sendo 94\% destes Travestis e Mulheres Trans. A subnotificação é alarmante quando se percebe que não existem dados oficiais do governo brasileiro, sendo necessário que a própria população afetada se organize em busca de informações a esse respeito (ANTRA, 2018). Fatores como idade, classe social, raça e gênero estão diretamente relacionados com a dificuldade de vida da população trans. Além de a maior parte das vítimas ter entre 16 e 29 anos, $80 \%$ das pessoas trans assassinadas se identificavam como negras ou pardas. Em $85 \%$ dos assassinatos foram Vol. 02, N. 04, Out. - Dez., 2019 - www.revistas.unilab.edu.br/index.php/rebeh 
apresentados requintes de crueldade: uso excessivo de violência, esquartejamentos, afogamentos, entre outras formas brutais de violência (ANTRA, 2018).

Estima-se que 13 anos é a média de idade em que pessoas trans são expulsas de casa RE Clo pais, encontrando-se em grande vulnerabilidade social muito cedo e expostas à vários '(IILCDCLip'os de violências (ANTRA, 2018). Como "a reapropriação do direito à vida é encarnada em suas ações" (ROLNIK, 2018, p.24) do cotidiano, se faz necessário pensar sobre algumas atividades, lugares e relações do dia-a-dia que influenciam diretamente a vida de pessoas trans. Como esses atravessamentos do social afetam a composição e sustentação da vida de pessoas trans?

\section{METODOLOGIA}

Esta pergunta faz parte de uma pesquisa maior intitulada "Performatividades dos corpos de pessoas trans", aprovada no dia 4 de Junho de 2018 pelo Comitê de Ética da Universidade La Salle com o número 87710118.5.0000.5307. Sendo assim, algumas informações foram utilizadas em outros contextos pelos autores. Foram realizadas três entrevistas semiestruturadas com pessoas que estão presentes em diferentes posições do espectro das identidades trans encontradas a partir da técnica de amostragem snowball. Havendo, assim, maior peso retórico à análise devido a heterogeneidade dos participantes (DEWES, 2013; NOGUEIRA, 2001).

Os entrevistados possuem entre 20 e 25 anos e residem na região metropolitana de Porto Alegre. Cristal é uma mulher trans graduada, educadora social, artista, casada e vive com esposa e filho. Saturno é uma trans não binária, natural do interior de outro estado, artista, graduanda e mora em uma casa de estudantes. Dani é um homem trans, graduando, professor e vive com seus pais. Serão utilizadas sempre as posições de identidade de gênero em que os próprios participantes se identificaram no momento da realização desta pesquisa. Os nomes dos participantes, junto de algumas informações pessoais, foram alteradas para manter uma relação de sigilo.

As transcrições de suas entrevistas serviram de corpus discursivo de uma Análise Crítica do Discurso, visando entender as formas de viver a identidade de gênero, o corpo, as representatividades que permeiam as vidas dos participantes em um contexto social. A Análise do Discurso com sua concepção de linguagem enquanto sistema fluido e instável, possibilitou refletir sobre as relações entre discursos, corpos, indivíduos e sociedade, fugindo de teorias homogeneizantes e dicotômicas (FOUCAULT, 1971; MORAES, 2010; DELEUZE, 2006). 
Serão realizadas citações diretas das entrevistas que articulam as ideias trazidas em cada discussão. Entre colchetes encontram-se informações pertinentes para contextualização da fala e as expressões em negrito ajudam a ressaltar termos importantes para o processo de análise.

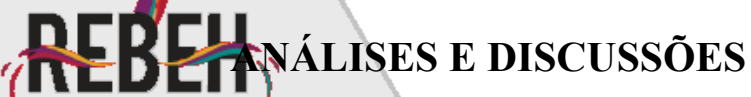

As entrevistas trouxeram materiais sobre diversos temas que foram agrupados em cinco categorias, que são: Te colocam no lugar que eles querem, no que eles pensam que é o teu lugar; Olha esse animal exótico que temos aqui em casa; A gente se soca na sociedade; Se soubessem que era uma pessoa trans será que iam me contratar? e Existe de usarem os corpos trans e não assumirem como relações. Os títulos são recortes das falas dos participantes.

\section{TE COLOCAM NO LUGAR QUE ELES QUEREM, NO QUE ELES PENSAM QUE É O TEU LUGAR}

As instituições médicas, assim como as jurídicas e educativas, se assentaram durante os últimos dois séculos sobre discursos heterocentrados à respeito dos corpos. Junto ao questionamento sobre qual o sexo do bebê durante a gravidez, se esconde um sistema que fixa uma ordem empírica que torna o corpo inteligível a partir de uma fragmentação dos órgãos. Assim, se define o sexo com relação a um determinado a priori anatômico-político buscando uma espécie de "coerência" naquele corpo. Essa primeira fragmentação vai tornar efetiva uma invocação performativa que resulta em uma delimitação dos corpos, órgãos, suas funções e sua utilização "normal" e "perversa". Entretanto, essa invocação não é apenas performativa, mas é prostética: faz os corpos (BUTLER, 2017; PRECIADO, 2017).

No momento em que um sujeito se entende de uma forma diferente àquela identidade fixada pelo sistema, ele pode buscar um conjunto de processos para "resolver a discordância entre sexo e gênero", mas essa se torna a segunda fragmentação desse corpo. A dificuldade de encontrar alguém que realize esses processos, assim como a violência que essas operações carregam e seu elevado custo econômico e social, expressam algumas das formas políticas de censura sexual. Essa segunda fragmentação exige um recorte físico do corpo que o redesenha para produzir uma nova coerência que deve ser sistemática como a anterior (PRECIADO, 2017).

A partir desse ponto de vista, um corpo só tem sentido se for sexuado. Assim, se constrói a binaridade de gênero a partir de um órgão sexual preciso, sendo estes os marcos abstratos que vão gerar uma totalidade do corpo. Nesta lógica, os órgão sexuais não são apenas 
os responsáveis pela reprodução humana, mas sim produtores de uma coerência do corpo como propriamente "humano" (PRECIADO, 2017).

Cristal

\section{유드태}

Uma mulher cis botar um silicone é uma intervenção cirúrgica super bem vista na sociedade. Os caras muitas vezes tomam hormônios masculinos pra fazer academia, criar músculo. Então, de certa forma muitas pessoas buscam mudanças no seu corpo pra se sentir bem. Só que as minhas vão pro lado do gênero oposto ao de nascimento, assim. E é visto como errado daí. Por que?

Ah, dá pra esconder [o pênis], dá pra usar um biquíni na praia. Na calça não pode marcar, tem que dar uma ajeitada nessa situação pra ter a "passabilidade". Mas as intervenções que existem hoje eu não acho seguras pra que tu tenha uma segurança de que tu vá sentir prazer depois, se vai ficar legal, não vai ter o risco de morrer na mesa de cirurgia, se tu vai sentir prazer. Então, por que que eu vou botar em xeque o meu prazer sexual por uma questão que em parte é estética? Pra algumas pessoas traz um pouco mais de incômodo, mas eu acho que ter um pênis não me faz menos mulher.

As identidades trans, e identidades que fogem à lógica cisheteronormativa, evidenciam a arbitrariedade dessas categorias. As marcas trazidas nos corpos mostram a relação próxima dessa categorização com a designação dos corpos que se constroem de maneira exclusiva e excludente. Os corpos sexuais que existem hoje são produtos de um estilo e desenho que utilizam de um juízo estético e de análise cromossômica para os descrever. A verdade do sexo é decidida em função de uma adequação (mudanças no seu corpo e intervenções arriscadas) à critérios heterossociais normativos, possuindo assim uma carga prescritiva de atribuição de sexo e, consequentemente, de gênero. Gera incômodo e "é visto como errado" pelos leitores desses corpos quando as normas não se fazem presentes ou não estão dispostas da maneira espera. A "passabilidade" se encontra nesse território regulamentado, levando - no caso de Cristal - à esconder o pênis (PRECIADO, 2017).

\section{Cristal}

Alguns lugares, mesmo que públicos, ainda te colocam no lugar que eles querem, no que eles pensam que é o teu lugar.

Essa falta de preparo [dos profissionais da saúde], a ignorância, vem de um preconceito né. Porque não quer saber como tratar uma trans quem acha que uma trans é um homem, porque a informação tá aí.

$\underline{\text { Dani }}$

Não tem muitos estudos [...] sobre pessoas trans idosas. Então não se sabe o que acontece com a gente quando a gente fica idoso. Pode ser que a gente tenha osteoporose, pode ser que não. Não se sabe, é uma coisa que é desconhecida.

As pessoas que tem essa especialidade de atender pessoas trans, ou a possibilidade de atender pessoas trans, é de 400 [reais] pra cima.

Hoje em dia se for num médico e falar, "Ó, eu sou trans e preciso fazer blábláblá...", eu vou falar, "não tenho conhecimento, não vou te atender". É possível. Então a gente [comunidade trans] tem uma lista de endócrinos, de psiquiatras, psicólogos e... de cirurgiões e de... ginecologistas que atendem pessoas trans.

As instituições médicas construídas neste sistema estão começando a se abrir e receber pessoas com identidades que diferem da lógica cisheteronormativa. Porém, os discursos acima Vol. 02, N. 04, Out. - Dez., $2019 \cdot$ www.revistas.unilab.edu.br/index.php/rebeh 
evidenciam a falta de preparo e de conhecimento de quem realiza essa assistência, além do distanciamento do atendimento especializado pela questão financeira. Torna-se clara a presença do preconceito e ignorância em profissionais da área da saúde, havendo uma RE CIdificuldade de lidar com o "diferente" e isso interfere diretamente na produção de um cuidado

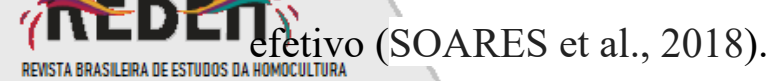

\section{OLHA ESSE ANIMAL EXÓTICO QUE TEMOS AQUI EM CASA}

A família é um núcleo de pessoas que convivem em determinado local, durante um tempo longo e que se encontram unidas (ou não) por laços consanguíneos. Estas instituições familiares variam e se transformam junto à época e contexto, existindo múltiplas ideias de o que é ou pode ser uma família. Independente da interpretação e composição de família escolhida, se sabe que ela é o primeiro grupo presente na vida de qualquer sujeito e deveria lhe transmitir características como afeto, cuidado, apoio e solidariedade, além de ser também quem primeiro vai apresentar os costumes e normativas sociais. A família, então, se torna determinante no desenvolvimento social, emocional e físico de cada pessoa, havendo um atravessamento constante e recíproco com influências de culturas e ideologias (PRADO, 2017; ZANARDO; VALENTE, 2018).

Contudo, as instituições familiares podem auxiliar na captura dos corpos visando disciplinar seus modos de vida aplicando suas forças no corpo orgânico, porém visando o corpo criativo e transformacional. Percebe-se que a partir de uma lógica de pensamento cisheteronormativa que estabelece um modelo majoritário uniformizando a subjetividade. Com isso, a diferença é concebida como um desvio desse modelo, levando à produção de "outros minoritários" sempre em resposta (NIGIANNI; STORR, 2005). As normas estabelecidas marcam os corpos através de estipulados padrões, controlam suas experiências e constroem territórios baseados em repetições comportamentais, aspectos corporais e lugares de “pertencimento" (DELEUZE, 1999; 2005; REGO, 2015).

\footnotetext{
Cristal

Quando eu botei no facebook que eu mudei o nome e falei que queria ser chamada assim e exigia, ele [pai] botou um monte de merda. Que, tipo, era falta de laço né. Aí depois por whatsapp ele me mandou coisas tipo, umas ameaças. Se ele me visse na rua ele ia me dar o coro, me dar o laço que eu não levei quando era criança. Que era por isso que eu tava assim.

Dani

"Ai olha, esse é o Dani. Olha esse animal exótico que temos aqui em casa", sabe? [...] Tinha toda parece que uma exibição, assim, eu era tipo uma exibição, assim. "Olha, o meu filho como está diferente".

Saturno
}

Vol. 02, N. 04, Out. - Dez., 2019 - www.revistas.unilab.edu.br/index.php/rebeh 
Uma parte [da minha família] que eu acho que é a mais, meio conservadora, e isso e aquilo, me vê como... que eu me exponho demais. E isso é fato, meus parentes vivem me falando, "você se expõe demais".

Quando eu vou visitar meus pais também isso ocorre bastante, tanto que muitos ainda me chamam pelo meu antigo nome, não fazem questão de me chamar pelo nome social. E aí eu sinto que eu perco a identidade, sabe? Eu sinto que... que é frustrante.

O sistema sexo-gênero e seus dispositivos são desafiados já que suas representações não são suficientes, gerando um estado de estranhamento à instituição familiar que podem produzir diversos efeitos. A diferença pode trazer a percepção de não se assemelhar à família, referindo-se ao filho como algo oposto ao humano e ao comum ou nativo daquele ambiente, um animal exótico. A família pode se transformar em uma instituição excludente e violenta trazendo explicações fantasiosas sobre a constituição da pessoa trans (falta de laço), tentando, a partir de intimidações e ameaças, resistir à novos modos de vida.

\section{A GENTE SE SOCA NA SOCIEDADE}

Como na maioria das relações interpessoais não há tempo suficiente para se dizer o que é e, como visto anteriormente, a identidade é buscada através de um juízo estético do corpo a partir de critérios normativos, há um investimento nessa composição corporal para legitimar uma existência. Entretanto, as interações ainda se dão com base em modelos pré-concebidos, o que pode impor composições de si baseadas nesses modelos para diminuir o desgaste, a violência e a deslegitimação dos corpos trans (RODOVALHO, 2017).

Cede-se aos padrões o quanto fizer sentido para a pessoa. Entretanto, essa composição não se faz apenas por uma "passabilidade" para abrigar-se na multidão evitando a transfobia, mas legitimar discursos reorganizando as categorias binárias de gênero e integrando-as, se assim for desejado; legitimar identidades baseadas em outros critérios que não os órgãos sexuais. Com isso, procura-se extinguir as estigmatizações, marginalização, desqualificações, assassinatos, intolerâncias, violências, psicopatologização e redução de suas identidades. Os discursos dos entrevistados expõe como pessoas cis ${ }^{3}$ projetam uma imagem do que pensam ser uma pessoa trans, ideias muitas vezes fantasiosas que não fazem jus à multiplicidade presente em suas existências (RODOVALHO, 2017; PRECIADO, 2017).

\footnotetext{
Dani

É muito raro eu falar pra pessoa que eu sou trans. Porque eu sei que as pessoas vão começar a me perceber de forma diferente, elas vão pensar, "então ele não tem pau", tá ligado? Tipo uns bagulho assim. E aí elas vão, tipo, a partir do momento que eu falar " eu sou trans" elas já vão pensar no genital, é automático.
}

\footnotetext{
${ }^{3}$ Expressão utilizada para pessoas em que o gênero é igual ao sexo biológico.
}

Vol. 02, N. 04, Out. - Dez., $2019 \cdot$ www.revistas.unilab.edu.br/index.php/rebeh 
As pessoas acham que quando elas veem uma pessoa trans elas são capazes de saber que elas são trans, sabe? E, se elas não sabem tu tá enganando elas, algo do tipo assim. Tipo assim, "ah eu sei saber se é um homem de verdade, entre aspas, ou se é uma mulher de verdade, entre aspas, eu sei definir isso, vocës não podem me enganar", tipo coisas assim, sabe?

Acontece das pessoas falar assim, "E tu já fez A cirurgia", A cirurgia. A cirurgia. [...] O que prova que é a primeira coisa que vem na cabeça delas. "Como será que é o genital?".

Eu queria avisar, só pra ser respeitado. E aí a minha sogra falou uma coisa que foi uma das piores coisas que eu já ouvi, assim, que foi tipo assim, "tem um padre que faz regressão...”. Ela queria que eu procurasse esse padre que faz regressão.

\section{$\underline{\text { Saturno }}$}

$\overline{\mathrm{Eu} \text { acho }}$ que se a pessoa não conversar comigo ela vai me tratar no masculino, pela questão, tipo, da barba. Eu acho que é muito forte o estigma da barba e também a ideia, tipo, da depilação, entendeu? Então, tipo, eu não me depilo, então vai... gera toda aquela coisa de que não teria como ser uma mulher, entendeu? Coisas do tipo.

Tem a... o susto, o choque, eu acho. Que quando eu tô de costa as pessoas... Tipo, por exemplo, se eu tô de costas e de vestido, super tranquilo, sabe? As pessoas passam... Aí na hora que eu viro, que eu tô com uma barba, com um batom, sabe? Daí a pessoa já [som de susto] e elas encaram, sabe? Tipo, os mais jovens, assim, os adolescentes não. Tem alguns até que param e falam assim, "ba que massa teu cabelo, que massa o teu estilo", sabe? Agora, umas pessoas de uns 40 anos assim, elas realmente olham.

Fui com uma sainha de crochê assim, bem curta. Depois a gente começou a andar pelo centro da cidade, daí as pessoas tiravam fotos. [...] Elas andando assim, sabe? Tiravam fotos e elas pensavam que eu não percebia, sabe?

Cristal

É muito dos olhares, é difícil dizer, mas quando tu sai na rua, assim, os olhares dizem muita coisa. As vezes que eu saio mais arrumada e tal é mais de boa, sabe? Pego o trem, sigo a minha viagem. Às vezes não, às vezes tô mais desarrumada, sem uma maquiagem. Saí e não consegui esticar a pele o suficiente pra fazer as barbichinhas direitinho - fica o chamado chuchu - e aí já aconteceu de senhora fazer o sinal da cruz pra mim.

Tipo, quando eu tô na rua. Acho que é essa busca pela "passabilidade". Pras coisas serem mais fáceis, pra me tratarem com o pronome correto.

A gente pode falar lá da universidade, ambiente acadêmico [...] Os professores super receptivos, super respeitosos. "Ah que bacana", que isso e aquilo. Os colegas também, numa maioria. É aquela bolha em que a discriminação tende a não acontecer tanto.

Aceita, não. Incluída? A gente se soca né. A gente se soca na sociedade, porque é como a gente quer ser, a gente tem que tá nos lugares, tem que tá na sociedade. É difícil dizer lugares que se sente confortável. [Silêncio] Eu não saberia dizer.

Percebe-se que o preconceito é vivido diariamente. As discriminações podem surgir com tentativas de regressão, com a perda de privacidade na rua onde pessoas tiravam fotos; com a dificuldade de inserção nos lugares levando a não se sentir aceita ou confortável; com a curiosidade a respeito da genitália das trans; com susto, choque e olhares; com as ideias limitantes de como deve ser uma pessoas trans e como ela deve se comportar - não teria como ser uma mulher, homem de verdade, mulher de verdade; com a imposição de "A cirurgia" para legitimar uma identidade. Essas, e outras, práticas de transfobia ampliam a segregação social em que as populações trans já se encontram. 


\section{SE SOUBESSEM QUE ERA UMA PESSOA TRANS SERÁ QUE IAM ME}

\section{CONTRATAR?}

A maioria das políticas públicas direcionadas às pessoas trans visa a prevenção de RE Cloenças sexualmente transmissíveis e o combate à exploração sexual, porém não parecem se

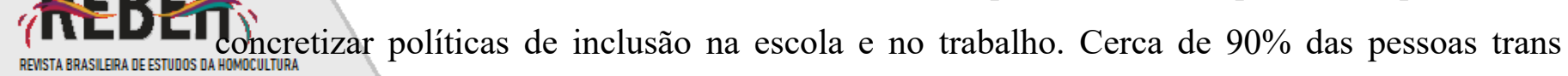
untilizam a prostituição como fonte de renda por conta da exclusão social que impossibilita melhor qualificação profissional - apenas $0,02 \%$ da população trans encontra-se na universidade (ANTRA, 2018).

\footnotetext{
$\underline{\text { Dani }}$

Por exemplo no trabalho, se soubessem antes que era uma pessoa trans será que iam me contratar? Então é uma coisa que tu tem que ter uma proteção pra tu conseguir continuar, sabe? Eu tenho muita vontade de contar pras pessoas, mas eu sei que as pessoas não vão entender como eu quero que elas entendam, sabe? Elas vão ver tipo, "ah ta o Dani não é quem a gente pensava. Ele é uma evolução de uma lésbica...", às vezes acontece.

Cristal

Pra conseguir estágio teve uma diretora "duma" escola aqui da cidade que me olhou da cabeça aos pés e me falou "não". E tinha vaga, eu sabia que tinha vaga. Entrevistas de emprego, eu sentia dificuldade de inserção no mercado de trabalho. Larguei 200 currículos, chamaram pra entrevista e fui descartada assim. Mesmo sabendo que tinha o currículo melhor que a maioria das pessoas que tavam ali ou que tinha pouca gente concorrendo. Mas é isso assim. E aí tem que buscar os lugares que são mais inclusivos, assim.

Me questionei muito se deveria fazer parte dessas políticas [afirmativas] porque eu tive os meus privilégios até uma boa parte da minha graduação. Mas aí eu pensei, "porra, o mercado de trabalho já tá super fechado pra mim, essa é uma das poucas alternativas que eu tenho, vamos usar o que temos porque daqui a pouco eu tô voltando pra sinaleira como única opção".
}

Sabendo que no Brasil o trabalho é um direito social e que essa população se encontra em situação de vulnerabilidade econômica e social, podemos perceber a dificuldade de acesso ao estudo e mercado de trabalho - eu sentia a dificuldade de inserção no mercado de trabalho, fui descartada assim, daqui a pouco eu tô voltando para a sinaleira como única opção. Vale ressaltar que há tentativas de buscar os lugares que são mais inclusivos e as políticas afirmativas é uma das poucas alternativas para sustentar a vida e desenvolver as habilidades. Para conseguir adentrar o mercado de trabalho, algumas pessoas trans podem omitir a questão de identidade de gênero para ter uma proteção e conviver de forma harmoniosa com colegas de trabalho. Este é o caso de Dani, mesmo trabalhando certo tempo na mesma instituição nenhum de seus colegas de trabalho sabe que ele é um homem trans (DE ALMEIDA; VASCONCELLOS, 2018).

\section{EXISTE DE USAREM OS CORPOS TRANS E NÃO ASSUMIREM COMO RELAÇÕES}

Vol. 02, N. 04, Out. - Dez., $2019 \cdot$ www.revistas.unilab.edu.br/index.php/rebeh 
A lógica cisheteronormativa, que busca uma "coerência" nos corpos através de critérios heterossociais normativos, se encontra presente de forma marcante na vida afetivo/sexual das pessoas trans. O modelo pré-concebido pode fazer com que sintam não ser o suficiente, não ser RE CLlleal o suficiente para a pessoa com quem está se relacionando, o que pode gerar a ideia de ter '(IILCLCI qu'e convencer uma pessoa para que esta ache "ok eu ser trans". Esse discurso traz a tona novamente o órgão sexual como centro organizador do corpo e determinante para legitimação da identidade (PRECIADO, 2017).

\begin{abstract}
$\underline{\text { Dani }}$
Eu tenho medo de não... de não ser o suficiente, de desapontar as pessoas por ser trans, numa relação sexual, sabe? Tipo, de não ser bom o suficiente, de não ser real o suficiente - olha que bizarro isso! Por que que não seria real, sabe?

Vai que um dia eu termino o meu namoro e aí como é que eu vou arrumar uma pessoa que acha ok eu ser trans? Como é que eu vou "convencer" uma pessoa de tentar ter algo comigo sabendo que eu sou trans?

Sim, porque as pessoas elas sabem que tu é trans já vai pensar "ah faltou [o pênis] então", faltou o principal , que nem falam.
\end{abstract}

O estigma presente influencia diretamente em suas relações. Começa-se a viver situações de assédio na rua, sendo frequente a fetichização do corpo trans, proposta de programa, os caras dando piscadinha, falando absurdos. Com isso, se evidencia a marginalização e objetificação dos corpos trans; o outro acaba por colocar a pessoa trans no lugar de mercadoria.

\footnotetext{
Cristal

Tava na estação e tive que usar o banheiro. Fui no masculino e um cara tira a piroca pra fora e começa a se masturbar na minha frente.

Mas na rua assim, comecei a viver situações de assédio, aquela coisa de fetichização do corpo trans, proposta de programa, os caras dando piscadinha, falando absurdos. Até às vezes quando eu tava de palhaça, às vezes ia pra sinaleira fazer uma grana, e acontecia propostas de programa quando eu tava de palhaça, entende? Então, muda o jeito que as pessoas te veem e as vezes o tratamento, assim.

Mas acho que as pessoas não assumem as relações [com pessoas trans] ou é aquela coisa de "ah, só curiosidade". Vai lá, transa duas, três, de vez em quando ou escondido. Acho que existe de usarem os corpos trans e não assumirem como relações, sendo que não muda nada né, assim, da pessoa.

Assumir a transição foi algo tão forte que, bom, eu sabia do risco de perder a minha esposa, sabe?
}

Outra situação presente nos discursos é a perda de relacionamentos. O assumir a transição parece produzir um estranhamento no outro com quem se relaciona, gerando risco de separação por não estar de acordo com o esperado (imposto) socialmente. Assim, a experimentação do corpo, o cuidado de si e a liberdade que esses processos produzem podem 
terminar um namoro ou fazer com que se conheça uma pessoa que incentive e apoie as descobertas do corpo e identidade.

\section{두드듀}

RENSTA BRASILERA DE ESTUDOS DA HOMOCULTURA $\underline{\text { Saturno }}$

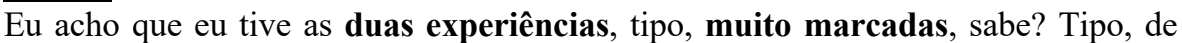
terminar um namoro por causa dessas questões de experiência do corpo e de conhecer um pessoa, e daí uma menina, que a gente começou a namorar assim, não foi um namoro sério, mas a gente começou a ficar e ela me incentivava, sabe, a descobrir meu corpo e não sei o que. [...] Ainda é complicado quando eu quero conversar com alguém ou quando eu quero conhecer e ficar com alguém, sabe?

Ao encontrar-se com alguém que o reconheça, incentive e ame, acaba se tornando difícil a constituição de família, principalmente se há o desejo de ter filhos. Para poder gerar um filho a pessoa trans ${ }^{4}$ precisará suspender a hormonização, o que terá efeitos em seu próprio corpo e na leitura social deste. Além disso, no caso de pessoas trans em relacionamentos homossexuais, o registro de um filho biológico se torna um processo legal por não haver como registrar duas mães ou dois pais. Neste caso, ainda há que lidar com a falta de conhecimento, transfobia e a descrença sobre sua identidade.

\begin{abstract}
Cristal
A gente deu tempo pra ela [esposa] pensar se ela queria ter uma namorada, uma esposa. E ver as questões de filho que era uma coisa que eu queria e ela também, era um plano futuro, a hormonização ia me impedir. E aí a gente antecipou...

Tive que adotar o meu próprio filho, mesmo sendo filho biológico. Não tinha uma lei que me amparasse.

A juíza pediu pra que eu mostrasse meu pênis, laudo médico, que a minha esposa comprovasse, falasse que teve uma relação [sexual] comigo, pra poder fazer o registro. Coisa que a gente se recusou a fazer. Mas aí a gente jogou, entramos com um processo. [...] Agora o Tribunal de Justiça publicou uma determinação que facilita o registro de filhos biológicos para pessoas trans.
\end{abstract}

\title{
ALGUMAS CONSIDERAÇÕES
}

A partir da análise dos discursos, evidencia-se que, não apenas a esfera sexual e relacional, mas todas as demais áreas de vida dessas pessoas foram penetradas pela lógica cisheteronormativa. Os corpos, a afetividade, a criatividade, a inteligência, foram todos colonizados, invadidos e expropriados pela sociedade. A existência, então, se encontra modulada por mecanismos que buscam a padronização da vida para seguir um modelo de otimização e intensificação de produção. Se torna difícil compreender onde estão esses mecanismos e quais são seus efeitos sobre a vida, pois os poderes chegam longe e fundo;

\footnotetext{
${ }^{4}$ Aqui se está falando de pessoas trans que não realizaram cirurgias de redesignação genital e/ou que conservam seu aparelho reprodutor.
}

Vol. 02, N. 04, Out. - Dez., $2019 \cdot$ www.revistas.unilab.edu.br/index.php/rebeh 
apropriam-se da potência de vida, da subjetividade e do desejo, capturando-os e vampirizandoos (PELBART, 2007; FOUCAULT, 2015; BUTLER, 2017).

Os poderes contemporâneos reduzem a vida a uma sobrevida e seus sujeitos a RE El obreviventes. A subjetividade foi reduzida ao corpo: a sua aparência, sua performance. É '(IILC DET probduzido um modelo inalcançável de corpo, de masculinidade, de feminilidade, de perfeição; corpos fascistas, diria Pelbart (2007). Modelos de performances, de identidades, que surgem como obrigatoriedades mas que ninguém consegue sustentar. Determinam a população que difere deste modelo como sub-humano, lançando-as a uma vida marginalizada. Porém, o corpo acaba não aguentando mais a docilização, a mutilação biopolítica, a modulação estética e sua redução ao biologicismo; decomposição niilista e mortificante (PELBART, 2007; FOUCAULT, 2015; BUTLER, 2017).

Assim, o que parecia inteiramente submetido aos poderes, pode surgir como reservatório de sentido, polifonia de modos de existir e germes que extrapolam as estruturas destes poderes. Como dizia Jards Macalé, “como é forte o gosto da farinha do desprezo, só vou

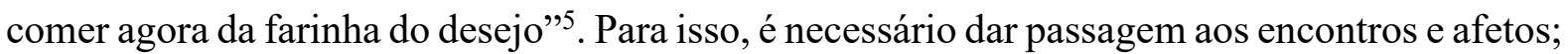
experimentar sua existência e se deixar ser atravessado. As artes parecem auxiliar na experimentação, libertação das forças inconscientes e composição de si. Parecem dar vazão a um processo de singularização que tem a potência de gerar novos modos de vida e atualizar as realidades das relações e dos corpos. A lógica cisheteronormativa e seus mecanismos são desafiados, ativando o que Suely Rolnik chama de corpo vibrátil: um corpo que experimenta a potência criadora do novo (PELBART, 2007; ROLNIK, 2006).

\footnotetext{
$\underline{\text { Saturno }}$

A arte, tipo, ela tá totalmente ligada à nossa composição, sabe, à nossa composição de personalidade. Então eu comecei a entender mais ou menos esses três fios né: da escrita, das fotos e do corpo, e comecei a misturar tudo e deu nisso. Tá dando ainda.

Cristal

E através do teatro veio aquela coisa das personagens femininas novamente e aí eu queria viver isso no teatro, mas ficava meio num canto assim. E aí com a palhaçaria eu... surgiu uma palhaça.

Aí comecei a fazer a palhaça pra vender comida. E aí eu via que todas as pessoas me olhavam quando eu entrava no transporte público. Aí eu lembrei dos debates, lembrei das problemáticas que trazia e eu pensei, "ba vou trazer um cartaz sobre aquelas violências que acontecem com a população LGBT" e comecei a querer mostrar isso pras pessoas, o quão errado era. Sem nem saber porquê tanto eu tava querendo defender e mostrar aquilo.

E dizem que o palhaço não é um personagem, é uma expressão máxima de ti, entende?

A minha feminilidade eu conseguia trazer na palhaça e era ótimo e eu às vezes queria passar mais tempo de palhaça do que não tá de palhaça.
}

\footnotetext{
${ }^{5}$ Versos retirados da música Farinha do desprezo, 1972, composição de Jards Macalé e Capinam.
}

Vol. 02, N. 04, Out. - Dez., 2019 - www.revistas.unilab.edu.br/index.php/rebeh 
São criadas, então, subjetividades flexíveis que acompanham experimentações de modos de existências e criações culturais que são indissociáveis de um devir-outro de si RE

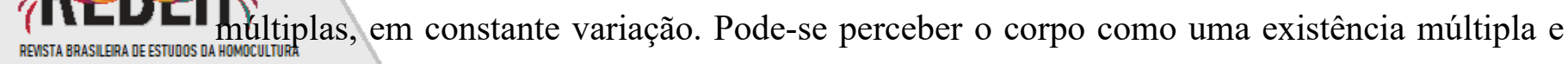
heterogênea; espaço de atravessamentos que se produz por seu movimento e capacidade de afetar e ser afetado. Além disso, a liberdade de experimentação surge na relação com o outro, uma atitude de escuta do mundo e de si mesmo (ROLNIK, 2006; DELEUZE; GUATTARI, 2010; 2011; 2012).

Os mecanismos biopolíticos não vão apenas estabelecer limites nas existências, mas vão gerar também novas subjetividades e performances que se apresentarão como resistência à ordem imposta. Com isso, se percebe que existem eventos de liberdade dentro das relações de poder, rompendo-as e construindo o novo. Há um esforço de reapropriação coletiva da potência da vida para, assim, compor “o comum”, esse campo de pulsão vital do corpo social que produz potencialidades coletivas das singularidades. Com a construção do comum as formas da realidade são transformadas em busca de uma reapropriação do direito de existir (ROLNIK, 2018; HARDT; NEGRI, 2016).

Cada área da vida trabalhada neste artigo é de fundamental importância para qualquer pessoa e por isso muitas pesquisas já foram realizadas, porém com foco na vida de pessoas trans ainda há poucos trabalhos. Pode-se perceber que existem, em cada uma destas áreas, detalhes que merecem ser investigados mais profundamente, o que poderia auxiliar na visibilidade e reconhecimento dos atravessamentos sociais que regulam as vidas de pessoas trans; que impossibilitam seus direitos de existir e que reduzem suas potências de vida.

\section{REFERÊNCIAS}

ASSOCIAÇÃO NACIONAL DE TRAVESTIS E TRANSEXUAIS - ANTRA. Mapa dos Assassinatos de Travestis e Transexuais no Brasil em 2017. 2018. Disponível em: $<$ https://antrabrasil.org/mapa-dos-assassinatos>. Acesso em: 20 mar. 2019. AMERICAN PSYCHOLOGICAL ASSOCIATION (APA). Guidelines for psychological practice with transgender and gender nonconforming people. Tradução de Ramiro Figueiredo Catelan e Angelo Brandelli Costa. American Psychologist, 70(9), 832-864. 2015. Disponível em: 
$<$ http://crprs.org.br/upload/others/file/35a995b2ba8493c19d715c00a03721bd.pdf $>$. Acesso em: 28 fev. 2019.

ARÁN, Márcia. A transexualidade e a gramática normativa do sistema sexo-gênero. Ágora: RE ELEstudos em Teoria Psicanalítica, Rio de janeiro, v. 9, n. 1, 2006. Disponível em: "TILㄴㄷㄴ?

$<$ http://www.scielo.br/scielo.php?script=sci_arttext\&pid=S1516-

14982006000100004\&lng=pt\&nrm=iso $>$. Acesso em: 8 mar. 2019.

BENTO, Berenice. A reinvenção do corpo: sexualidade e gênero na experiência transexual. Rio de Janeiro: Garamond, 2006.

Sexualidade e experiências trans: do hospital à alcova. Ciência \& Saúde Coletiva,

Rio de Janeiro, v. 17, n. 10, p. 2655-2664, 2012. Disponível em: $<$ http://www.redalyc.org/articulo.oa?id=63024360015>. Acesso em: 20 mar. 2019.

BUTLER, Judith. Problemas de gênero: Feminismo e subversão da identidade. Rio de Janeiro: Civilização Brasileira, ed. 15, 2017.

BRASIL. Ministério do Trabalho. Portaria N. 2.803, de 19 de Novembro de 2013. Redefine e amplia o Processo Transexualizador no Sistema Único de Saúde (SUS). Diário Oficial da União da República Federativa do Brasil. Brasília, 20 nov. 2013.

CIDADE, Maria Luiza Rovaris; BICALHO, Pedro Paulo Gastalho. A racionalidade médicojurídica dos processos de alteração do registro civil de pessoas trans no estado do Rio de Janeiro. Revista de Direito, v. 9, n. 02, p. 161-203, 2017.

CONSELHO NACIONAL DE DE JUSTIÇA. Provimento N. 73. de 28 de Junho de 2018. Disponível em: <http://www.cnj.jus.br/busca-atos-adm?documento=3503> . Acesso em:

DE ALMEIDA, Cecília Barreto; VASCONCELlOS, Victor Augusto. Transexuais: transpondo barreiras no mercado de trabalho em São Paulo?. Revista Direito GV, v. 14, n. 2, p. 302-333, 2018. Disponível em: $<$ http://bibliotecadigital.fgv.br/ojs/index.php/revdireitogv/article/view/77103>. Acesso em: 20 mar. 2019.

DELEUZE, Gilles. ¿Que és un dispositivo? In: BALIBAR, Etinenne; DREYFUS, Hubert; DELEUZE, Gilles et al. Michel Foucault, filósofo. Barcelona: Gedisa, p. 155- 163, 1999.

Foucault. São Paulo: Brasiliense, 2005.

DELEUZE, Gilles; GUATTARI, Félix. O Anti-Édipo. São Paulo: 34, 2010.

Mil platôs: Capitalismo e Esquizofrenia, vol. 3. São Paulo: 34. 2011.

Mil Platôs: Capitalismo e Esquizofrenia, vol. 4. São Paulo: 34. 2012.

DEWES, João Osvaldo. Amostragem em Bola de Neve e Respondent-Driven Sampling: uma descrição dos métodos. 2013. 52f. Trabalho de Conclusão de Curso (Bacharel em Vol. 02, N. 04, Out. - Dez., 2019 · www.revistas.unilab.edu.br/index.php/rebeh 
Estatística) - Instituto de Matemática, Universidade Federal do Rio Grande do Sul,

Departamento de Estatística, Porto Alegre, 2013.

FOUCAULT, Michel. Vigiar e punir. Petrópolis: Vozes, 1999.

A arqueologia do saber. 6. ed. Petrópolis, RJ: Vozes, 2002.

História da sexualidade I: a vontade de saber. São Paulo: Paz e Terra, ed. 1, 2014. Microfísica do poder. 2. ed. Rio de Janeiro: Paz e Terra, 2015.

GUATTARI, Félix; ROLNIK, Suely. Micropolítica: Cartografias do desejo. Petrópolis: Vozes, ed. 11, 2013.

HARDT, Michael; NEGRI, Antonio. Bem-estar comum. Rio de Janeiro: Record, 2016.

LUCKMANN, Felipe; NARDI, Henrique Caetano. Um corpo (des) governado: hierarquias de gênero, governamentalidade e biopolítica. Estudos Feministas, v. 25, n. 3, p. 1239-1255, 2017. Disponível em: <https://www.jstor.org/stable/90013349>. Acesso em: 20 fev. 2019.

NIGIANNI, Chrysanthi; STORR, Merl. Deleuze and queer theory. Edinburgh University Press, 2005.

NOGUEIRA, Conceição. Análise do discurso. In. FERNANDES, Eugénia; ALMEIDA, Leandro. Métodos e técnicas de avaliação: contributos para a prática e investigação psicológicas. Universidade do Minho: Centro de Estudos em Educação e Psicologia, 2001.

PELBART, Peter Pál. Biopolítica. Sala Preta, v. 7, p. 57-66, 2007. Disponível em:

PRADO, Danda. O que é família. Brasiliense, 2017.

PRECIADO, Paul. Manifesto Contrassexual: práticas de subversão da identidade. São Paulo: n-1 edições, 2017.

REGO, Francisco Cleiton Vieira Silva do. Viver e esperar viver: corpo e identidade na transição de gênero de homens trans. 2015. 188f. Dissertação (Mestrado em Antropologia Social) - Centro de Ciências Humanas, Letras e Artes, Universidade Federal do Rio Grande do Norte, Natal, 2015.

RODOVAlHO, Amara Moira. O cis pelo trans. Revista de Estudos Feministas, v. 25, n. 1, p. 365-373, 2017. Disponível em:

$<\mathrm{ttp}: / /$ www.scielo.br/scielo.php?script=sci_arttext\&pid=S0104-

026X2017000100365\&lng=en\&nrm=iso>. Acesso em: 21 fev. 2019.

ROLNIK, Suely. Geopolíticas da Cafetinagem. Núcleo de Estudos da Subjetividade, São Paulo, 2006. Disponível em: <http://www.crprj.org.br/site/wpcontent/uploads/2016/04/direitoshumanos.pdf\#page=103>. Acesso em: 22 de outubro de 2018. Esferas da insurreição: notas para uma vida não cafetinada. N-1 edições, 2018.

Vol. 02, N. 04, Out. - Dez., 2019 · www.revistas.unilab.edu.br/index.php/rebeh 
SOARES, Luciano Silveira et al. Cuidado em saúde e transfobia: percepções de travestis e transexuais de duas regiões do Rio de Janeiro: Maré e Cidade de Deus, sobre os serviços de saúde. 2018. 100f. Dissertação (Mestrado em Saúde Pública) - Fundação Oswaldo Cruz, DCEscola Nacional de Saúde Pública Sergio Arouca, Programa de Pós-Graduação em Saúde

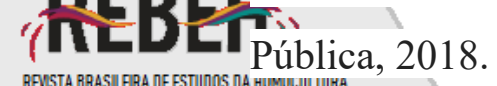

ZANARDO, Larissa; VALENTE, Maria Luisa Louro Castro. Família e gênero na contemporaneidade. Revista de Psicologia da UNESP, v. 8, n. 2, p. 5-5, 2018.

Recebido em: 02/04/2019

Aprovado em: 10/01/2020

Vol. 02, N. 04, Out. - Dez., 2019 - www.revistas.unilab.edu.br/index.php/rebeh 